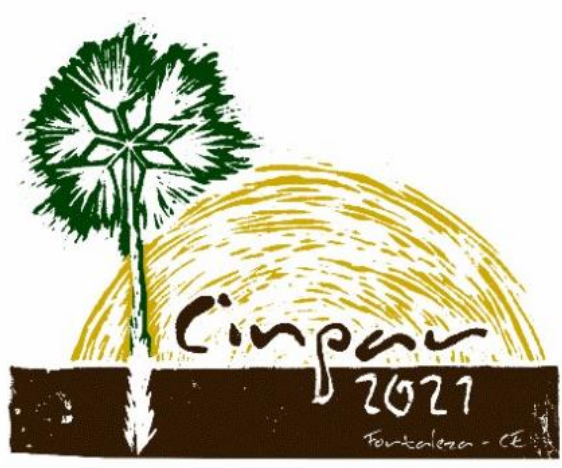

XVII Congresso Internacional sobre Patologia e

Reabilitação das Construções

XVII Congreso Internacional sobre Patología y Rehabilitación de las Construcciones

XVII International Conference on Pathology and Constructions Rehabilitation

FORTALEZA (Brasil), 3 a 5 de junho de 2021

https://doi.org/10.4322/CINPAR.2021.016

\title{
Estudo do uso de argila expandida para a produção de concreto leve
}

\section{Study of the use of expanded clay for the production of lightweight concrete}

\author{
Michele A. MOMBERG ${ }^{1}$, Jaquelline S. FEITOZA ${ }^{2}$, Paulo P. O. L. DYER ${ }^{3}$, Julia W. LENCIONI ${ }^{4}$, Carlos E. T. \\ BALESTRA $^{5}$, Gustavo J. L. COPPIO ${ }^{6}$

\footnotetext{
${ }^{1}$ Instituto Federal de São Paulo, Itapetininga, Brasil, michele.momberg@aluno.ifsp.edu.br

2 Instituto Federal de São Paulo, Itapetininga, Brasil, jaquelline.feitoza@ifsp.edu.br

${ }^{4}$ Universidade do Vale do Paraíba, São José dos Campos, Brasil, jlencioni@univap.br

${ }^{5}$ Universidade Tecnológica Federal do Paraná, Toledo, Brasil, carlosbalestra@utfpr.edu.br

${ }^{6}$ Instituto Federal de São Paulo, Itapetininga, Brasil, gustavo.coppio@ifsp.edu.br
} \\ ${ }^{3}$ Instituto Tecnológico da Aeronáutica, São José dos Campos, Brasil, paulo_dyer@yahoo.com
}

\begin{abstract}
Resumo: O desenvolvimento e aprimoramento de materiais sustentáveis para a construção civil tem sido objeto de diversos estudos. Dentre os inúmeros materiais que possibilitam minimizar os impactos ambientais, o concreto leve produzido com argila expandida tem demonstrado ser uma alternativa ao uso em larga escala do concreto convencional. O concreto leve, produzido com agregado graúdo de argila expandida, possibilita uma menor massa específica, um melhor conforto acústico e um maior isolamento térmico, o que resulta na redução do consumo energético com o uso de sistemas de climatização ambiente. Também pode contribuir para a redução dos custos da construção, pois sua menor massa específica possibilita a execução de edificações mais leves e com menores dimensões dos elementos estruturas, diminuindo o consumo de materiais, ainda que o concreto leve seja utilizado para fins não estruturais, como a sua aplicação em contrapisos de lajes. Neste estudo, foram utilizadas argilas expandidas fabricadas em laboratório e argilas expandidas comercializadas no mercado, como agregados graúdos para a confecção de concreto leve. O objetivo foi realizar a produção de argila expandida, por meio de um processo rápido, ou seja, a argila foi moldada manualmente, seca em estufa e exposta a uma temperatura de $900{ }^{\circ} \mathrm{C}$ por apenas 30 minutos, para então avaliar a resistência à compressão dos concretos confeccionados com as argilas expandidas. Para esta finalidade, foram moldados corpos de prova de concreto com a substituição de $100 \%$ do agregado graúdo convencional pela argila expandida fabricada em laboratório e por uma argila expandida comercializada na região de Itapetininga, tendo sido determinadas e comparadas as suas resistências à compressão aos 7, 14 e 28 dias de idade. Os resultados mostraram que o concreto leve confeccionado com a argila produzida em laboratório obteve resistência à compressão semelhante ao das amostras com argilas comercializadas.
\end{abstract}

Palavras-chave: Argila expandida, Sustentabilidade, Concreto leve.

\begin{abstract}
The development and improvement of sustainable materials for civil construction has been the subject of several studies. Among the numerous materials that allow to minimize environmental impacts, lightweight concrete produced with expanded Clay has been shown to be an alternative to the large-scale use of conventional concrete. Lightweight concrete, produced with coarse expanded Clay aggregate, allows for a lower specific mass, better acoustic comfort and greater thermal insulation, which results in reduced energy consumption with the use of ambient air conditioning systems. It can also contribute to the reduction of construction costs, because its lower specific mass allows the execution of lighter buildings and with smaller dimensions of the structural elements, decreasing the consumption of materials, even though
\end{abstract}


lightweight concrete is used for non-structural purposes, such as its application on counterfloor on slab. In this study, expanded clays manufactured in the laboratory and expanded clays commercialized on the market were used as coarse aggregates for making light concrete. The objective was to produce expanded Clay using a fast process, that is, the Clay was molded by hand, kiln dried and exposed to a temperature of $900{ }^{\circ} \mathrm{C}$ for only 30 minutes, and to evaluate the compressive strength of concrete made with expanded Clays For this purpose, concrete specimens were molded with the replacement of $100 \%$ of the conventional coarse aggregate by the expanded Clay manufactured in the laboratory for this study and by an expanded Clay sold in the Itapetininga region, having been determined and compared its resistance to compressive strength at 7,14 and 28 days of age. The results showed that the lightweight concrete made with the Clay produced in the laboratory obtained resistance to compression similar to that of the samples with commercialized Clays.

Keywords: Expanded Clay, Sustainability, Lightweight concrete.

\section{Introdução}

A construção civil constitui uma das mais importantes atividades da sociedade, entretanto, é responsável por gerar grandes quantidades de resíduos sólidos decorrentes das construções e demolições, podendo chegar a $50 \%$ de toda a produção de resíduos sólidos urbanos (CARDOSO, 2017). Esta atividade também é responsável por um elevado consumo de materiais extraídos de fontes não renováveis (BOLDRIN et al., 2012), tais como o uso de areia e brita para a utilização como agregados para o concreto.

Diante dos impactos gerados pela indústria da construção civil ao meio ambiente, há uma crescente necessidade de desenvolvimento e aprimoramento de materiais sustentáveis para a construção civil, assim como a aplicação de novas técnicas e métodos construtivos, visando minimizar as degradações ambientais causadas por essa atividade de suma importância para a economia e o desenvolvimento de um país.

Neste contexto, a argila expandida tem demonstrado ser uma boa alternativa para minimizar os impactos ambientais decorrentes do uso em larga escala do agregado graúdo convencional, cujo mesmo consiste em um recurso natural não renovável. Ademais, a utilização da argila expandida na fabricação de concreto resulta na obtenção de um concreto leve (RASHAD, 2018).

No processo de fabricação, a argila, após a moldagem e secagem, é colocada em forno às altas temperaturas, que variam entre $1100^{\circ} \mathrm{C}$ a $1300^{\circ} \mathrm{C}$. Durante este período, ocorre a queima dos compostos orgânicos e a liberação de gases, que fazem com que haja a expansão do material, produzindo um material cerâmico poroso, leve e resistente (ALEXANDER et al., 1999).

Assim, o concreto leve, apesar de apresentar redução da resistência mecânica na medida em que se aumenta o teor de substituição do agregado convencional pela argila expandida (REAL et al., 2015), pode contribuir para a redução dos custos da construção, pois a menor massa específica possibilita a execução de edificações com menores dimensões dos elementos estruturas, ou seja, mais leves, diminuindo o consumo de materiais, ainda que a aplicação do concreto leve seja para fins não estruturais.

O uso da argila expandida como agregado graúdo para obtenção de concreto leve também proporciona uma redução da absorção e transferência de calor (SACHT et al., 2010), possibilitando um maior isolamento térmico, e uma redução do consumo energético com o uso de sistemas de climatização ambiente. Sacht et al. (2010) ao estudar o comportamento da condutividade térmica de concretos leves produzidos com argila expandida, observaram uma correlação entre a massa específica do concreto e a condutividade térmica do material, ou seja, quanto maior a massa específica, maior é a condutividade térmica. Além de proporcionar um melhor conforto térmico, a argila expandida também contribui para um maior conforto acústico, devido à grande porosidade com inúmeras pequenas cavidades preenchidas com ar incorporado (RASHAD, 2018). Neste sentido, muitas pesquisas sobre o uso de argilas expandidas para a produção de concreto leve têm sido realizadas, como os recentes estudos de Burbano-Garcia et al. (2021) e Roufael et al. (2021).

Neste estudo, foi utilizada uma argila expandida comercializada na Região de Itapetininga, e também foi realizada a fabricação de uma argila expandida em laboratório, por meio de um processo rápido, submetendo a argila moldada e seca a uma temperatura de $900{ }^{\circ} \mathrm{C}$, por apenas 30 minutos, com o objetivo de comparar a aplicação das mesmas como agregado graúdo para a produção de concreto leve. Visando avaliar a resistência à compressão dos concretos confeccionados com cada uma destas argilas expandidas, foram 
moldados corpos de prova de concretos com a utilização das argilas, utilizando a mesma proporção em massa dos materiais do traço da mistura.

Os corpos de prova de concreto leve, moldados com a substituição de $100 \%$ do agregado graúdo convencional pelos dois tipos de argila estudadas, foram submetidos aos ensaios de determinação da resistência à compressão aos 7, 14 e 28 dias de idade a fim de analisar o comportamento e o resultado entre as duas argilas utilizadas, além de avaliar os efeitos e a qualidade da argila fabricada em laboratório em relação às existentes no mercado. Este trabalho pretende contribuir com a fabricação de concreto leve, visando o estudo do desenvolvimento e aprimoramento de materiais alternativos para aplicação na construção civil, de forma a possibilitar uma maior sustentabilidade ambiental desta atividade de suma importância para toda a sociedade.

\section{Metodologia}

As etapas e ensaios realizados no program experimental deste presente estudo são apresentados no fluxograma da Figura 1.

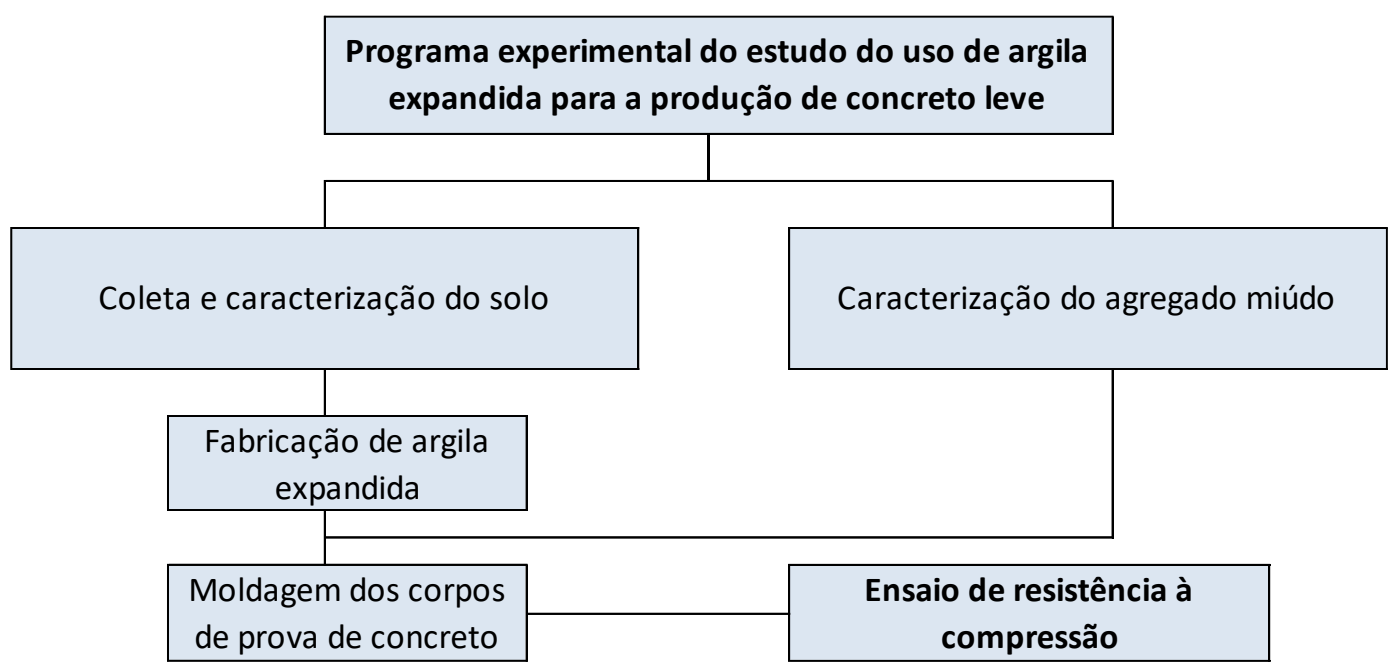

Figura 1 - Fluxograma das etapas e ensaios do programa experimental.

A caracterização dos agregados, a moldagem dos corpos de prova e a metodologia dos ensaios realizados encontram-se descritos em subtítulos próprios, apresentados a seguir.

\subsection{Caracterização do solo e o procedimento de fabricação da argila expandida}

O solo utilizado para a fabricação da argila expandida em laboratório foi coletado e preparado conforme a norma técnica da Associação Brasileira de Normas Técnicas (ABNT NBR 6457, 2016), determinando-se o teor de umidade no estado natural e a massa específica (ABNT NBR 7182, 2016). Também foram realizados os ensaios para determinação dos limites de liquidez e plasticidade, de acordo com a metodologia das normas técnicas da ABNT NBR 6459 (2016) e NBR 7180 (2016), respectivamente. Os valores obtidos pelos ensaios de caracterização do solo são apresentados no Quadro 1.

Para o preparo da argila expandida, o solo utilizado foi seco em estufa, a uma temperatura de $105^{\circ} \mathrm{C}$, até a constância de massas e, após o resfriamento, foram adicionados 35 \% de água em relação à massa de solo seco, procedendo-se a misturação até atingir a homogenização e plasticidade adequada para moldar as esferas de argila.

Após o preparo das esferas de argila, as mesmas foram colocadas em uma mufla e submetidas a uma temperatura de $900{ }^{\circ} \mathrm{C}$ durante um període de 30 minutos, e na sequência, procedeu-se o resfriamento gradual. 
Quadro 1 - Resultados dos ensaios de caracterização do solo utilizado para a fabricação de argila expandida.

\begin{tabular}{|c|c|}
\hline Propriedade & Dado \\
\hline Teor de umidade $(\mathrm{W})$ & $10,3 \%$ \\
\hline Massa específica aparente seca $(\rho d)$ & $0,979 \mathrm{~g} / \mathrm{cm}^{3}$ \\
\hline Limite de liquidez (LL) & $47 \%$ \\
\hline Limite de plasticidade (LP) & $36 \%$ \\
\hline
\end{tabular}

Na Figura 2 podem ser observadas as etapas do processo de fabricação a partir da argila moldada.

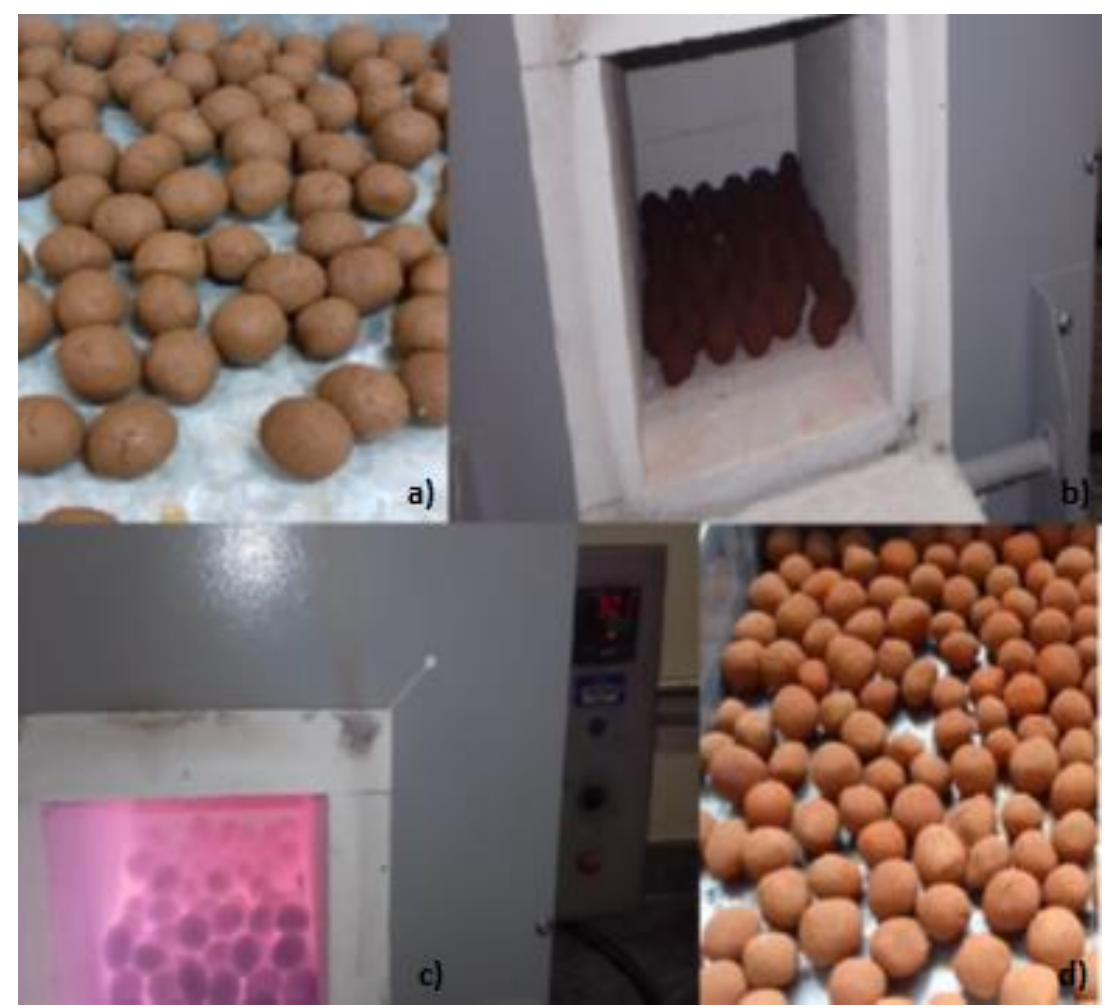

Figura 2 - Apresentação do procedimento de fabricação da argila expandida, onde se tem: a) argila moldada; b) argila colocada na mufla; c) argila sob a temperatura de $900^{\circ} \mathrm{C}$; d) argila expandida.

A argila expandida comercial possuia como característica uma superfície lisa, enquanto a argila expandida produzida apresentou uma superfície áspera. Já o diâmetro máximo característico destes agregados (DMC), determinado conforme o método da ABNT NBR NM 248 (2003) e NBR 7211 (2009), foi de $19 \mathrm{~mm}$ para ambas as argilas expandidas estudadas. Na Figura 3 são mostradas imagens das duas argilas expandidas estudadas.

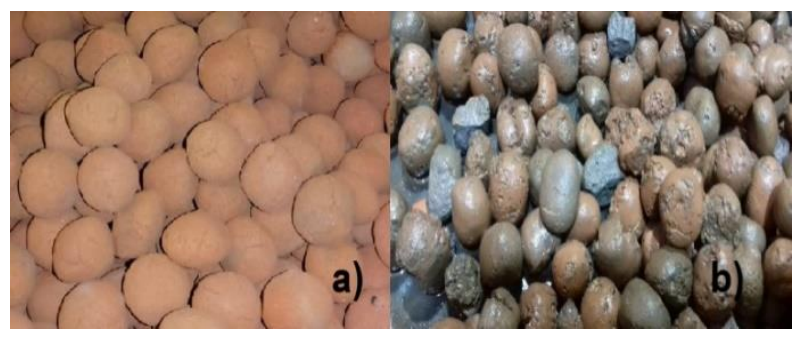

Figura 3 - Imagem das argilas expandidas estudadas: a) argila fabricada para esta pesquisa; b) argila expandida comercial. 


\subsection{Agregado miúdo}

O agredado miúdo (areia natural), utilizado para a moldagem das amostras de concreto, foi submetido a ensaios de caracterização, de acordo com a metodologia das Normas Técnicas Brasileiras (NBR) e Normas MERCOSUL, adotado pela Associação de Normas Técnicas (ABNT). No Quadro 2 são apresentados os ensaios e as metodologias das normas técnicas aplicadas na caracterização das propriedades do agregado miúdo, e, no Quadro 3, são mostrados os resultados dos ensaios de caracterização.

Quadro 2 - Ensaios de caracterização do agregado miúdo (areia natural) e as respectivas normas técnicas adotadas.

\begin{tabular}{|c|c|}
\hline Ensaio & Norma Técnica \\
\hline $\begin{array}{l}\text { Determinação da composição granulométrica - } \\
\text { Diâmetro Máximo do Agregado e Módulo de Finura }\end{array}$ & $\begin{array}{l}\text { ABNT NBR NM } 248(2003) \text { e } \\
\text { NBR } 7211(2009)\end{array}$ \\
\hline Determinação da absorção de água & ABNT NBR NM 30 (2001) \\
\hline Determinação da massa unitária & ABNT NBR NM 45 (2006) \\
\hline $\begin{array}{l}\text { Obtenção da massa específica e massa específica } \\
\text { aparente }\end{array}$ & ABNT NBR NM 52 (2009) \\
\hline Material fino que passa na peneira $75 \mu \mathrm{m}$ por lavagem & ABNT NBR NM 46 (2011) \\
\hline
\end{tabular}

Quadro 3 - Características do agregado miúdo.

\begin{tabular}{|c|c|}
\hline Propriedade & Dado \\
\hline Módulo de finura & 2,45 \\
\hline Diâmetro máximo do agregado $(\mathrm{mm})$ & 2,36 \\
\hline Massa específica aparente $\left(\mathrm{g} / \mathrm{cm}^{3}\right)$ & 2,15 \\
\hline Massa específica sss $\left(\mathrm{g} / \mathrm{cm}^{3}\right)$ & 2,24 \\
\hline Massa específica $\left(\mathrm{g} / \mathrm{cm}^{3}\right)$ & 2,36 \\
\hline Massa unitária $\left(\mathrm{g} / \mathrm{cm}^{3}\right)$ & 1,50 \\
\hline Absorção de água $(\%)$ & 2,7 \\
\hline Material pulverolento $(\%)$ & 1,9 \\
\hline
\end{tabular}

\subsection{Moldagem dos corpos de prova}

Para cada tipo de argila expandida utilizada neste estudo, ou seja, a fabricada e a disponível no comércio local, foram preparados e moldados corpos de prova de concreto, com um traço em massa de 1: 1,7: 2 e relação água/cimento de 0,65, com a substituição de 100 \% do agregado graúdo convencional pelas argilas estudadas em cada variação de amostras. Para a mistura do concreto, utilizou-se o cimento CP II-F.

Os corpos de prova foram moldados em formas cilíndricas de $100 \times 200 \mathrm{~mm}$, e após as primeiras 24 horas de cura, foram submetidos à cura submersa, sendo retirados da submersão somente para a realização dos ensaios de resistência à compressão.

\subsection{Ensaios de resistência à compressão}

O ensaio de resistência à compressão foi realizado conforme a metodologia estabelecida pela norma técnica brasileira, a ABNT NBR 5739 (2018). Os ensaios para cada uma das variações de amostras foram realizados nas seguintes idades: 7, 14 e 28 dias.

Para eliminar as irregularidades superficiais dos corpos de prova que pudessem interferir nos resultados dos ensaios, devido a uma eventual concentração de tensões decorrentes da rugosidade superficial, foram colocados discos de neoprene de $7 \mathrm{~mm}$ de espessura sob as faces superiores e inferiores de cada amostra. Na Figura 4 são apresentadas imagens da execução do ensaio de compressão. 
Para cada variação de amostra estudada, foi utilizado dois corpos de prova por idade em cada ensaio, obtendo-se o valor da resistência à compressão a partir da média dos resultados.

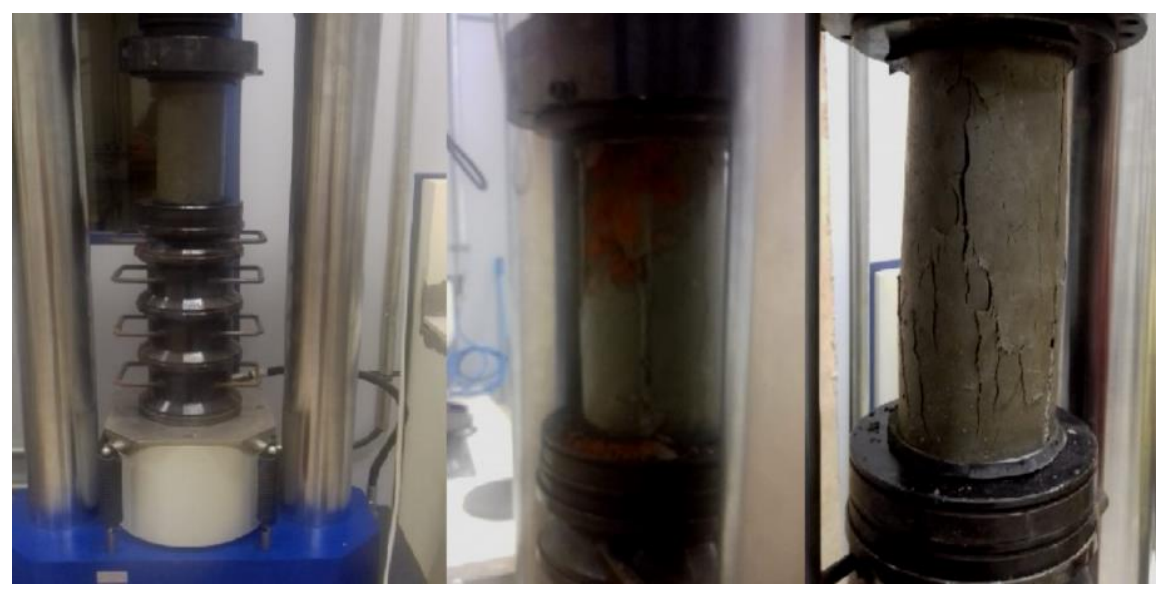

Figura 4 - Ensaio de resistência à compressão em execução.

\section{Resultados e discussões}

Os resultados dos ensaios de resistência à compressão dos concretos leves, preparados com $100 \%$ de substituição do agregado graúdo pelas argilas expandidas, são apresentados neste capítulo, comparando os resultados das amostras de concreto que utilizaram na sua mistura a argila fabricada nesta pesquisa (CAF) e a argila comercial adquirida no mercado local (CAC).

Os corpos de prova das duas variações de amostras foram mantidos sob cura submersa em água, a partir das 24 horas após a moldagem, sendo que os exemplares somente foram retirados da submersão para serem submetidos aos ensaios de resistência à compressão, ou seja, aos 7, 14 e 28 dias de idade. Os resultados apresentados foram obtidos através da média aritmética.

O gráfico da Figura 5 mostra os resultados dos ensaios de compressão dos exemplares de concreto preparados com os dois tipos de argilas utilizadas nesta pesquisa. Como pode ser observado no gráfico da Figura 5, ambos os concretos leves apresentaram ganho de resistência conforme avanço do processo de cura e idade dos materiais, o que demonstra que a utilização das argilas expandidas como agregado graúdo não interferiu no comportamento do processo de cura durante os 28 dias de idade dos concretos leves, período em que foram realizados os ensaios de resistência à compressão.

Considerando que as argilas expandidas têm como característica uma elevada porosidade e absorção de água (ALEXANDER et al., 1999; RASHAD, 2018), não obstante os corpos de prova serem submetidos à cura submersa em água somente após as primeiras 24 horas, contadas a partir da moldagem, este período inicial de cura dos concretos também não foi afetado pela absorção de água das argilas. Isso porque não se observou uma fragilidade superficial das amostras, conforme pode ser observado na Figura 4, que mostra o tipo de ruptura apresentada pelos exemplares confeccionados com ambas as argilas utilizadas: ruptura cônica bipartida, conforme a ABNT NBR 5739 (2018). Assim, as fraturas não se concentraram nas superfícies de contato. Segundo Helene e Levy (2013), a interrupção da cura pela falta de água, pode gerar, como efeito negativo, a perda de resistência superficial do concreto.

Os valores de resistência média à compressão dos concretos preparados com a argila expandida fabricada (CAF) e com a argila expandida comercial (CAC), conforme mostra o gráfico da Figura 5, apresentaram resultados semelhantes em todas as idades, onde as amostras de CAF apresentaram uma resistência à compressão um pouco mais elevada que as amostras de CAC somente no ensaio realizado aos 7 dias de idade das amostras. Este fato demostra que o processo de fabricação da argila expandida utilizado neste trabalho, onde a argila foi exposta por apenas 30 minutos a uma temperatura de $900{ }^{\circ} \mathrm{C}$, mostrou ser eficaz para a obtenção de um produto final, que conferiu ao concreto leve uma resistência mecânica à compressão semelhante ao proporcionado pelo concreto com a utilização da argila comercial em sua mistura. 


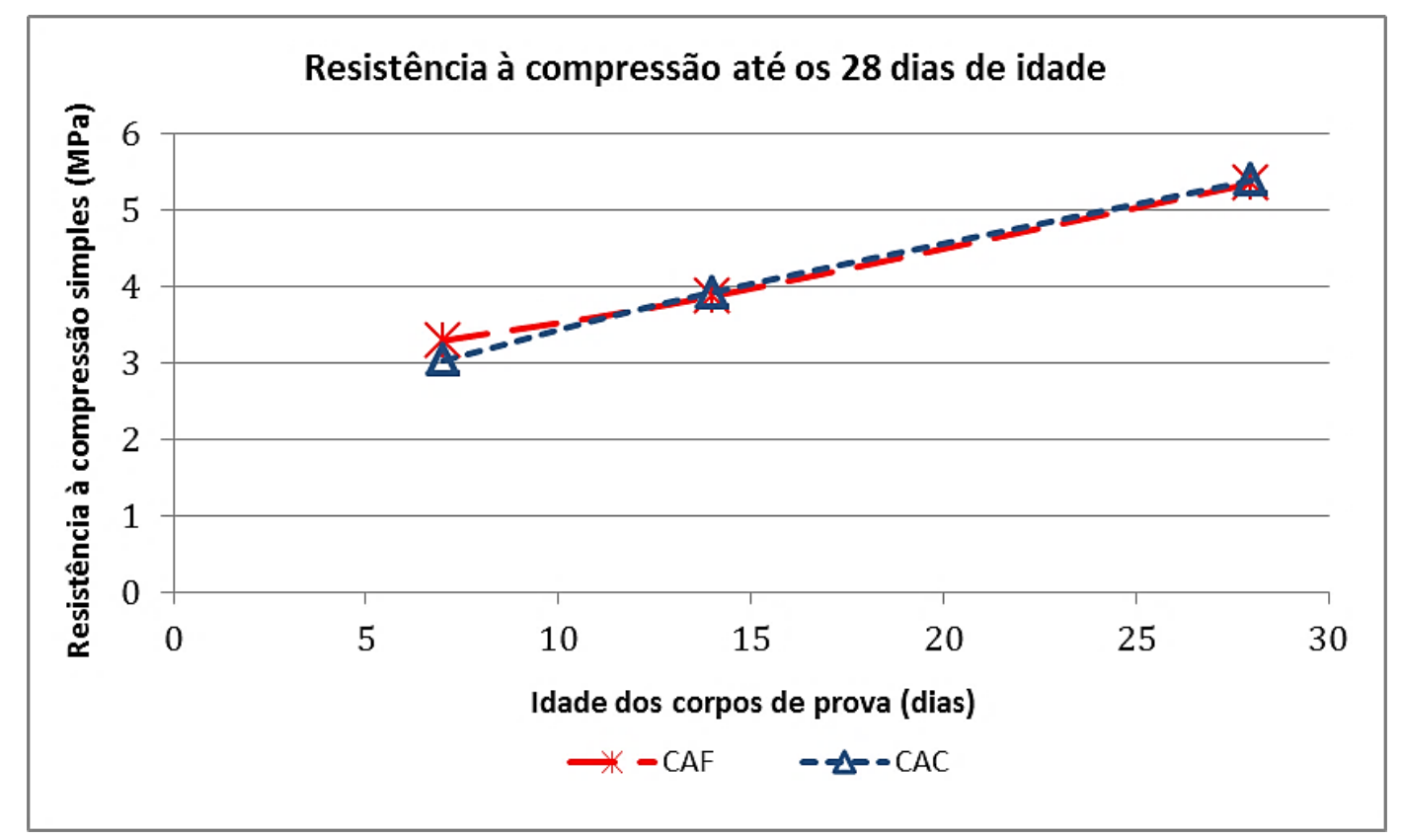

Figura 5 - Valores dos resultados dos ensaios de resistência à compressão do concreto com argila expandida fabricada (CAF) e do concreto com argila expandida comercial (CAC).

Por outro lado, como mostra a Figura 5, os valores de resistência média à compressão obtida por ambas as variações das amostras não foram suficientes para se considerar o uso para fins estruturais. Este fato possivelmente decorre do traço adotado para as amostras, que contém uma elevada relação água/cimento (a/c): 0,65. Um maior fator a/c ocasiona uma menor resistência mecânica ao concreto (NEVILLE E BROOKS, 2013). A subtituição total do agregado graúdo convencional pelas argilas expandidas também contribuiu para a redução da resistência à compressão do concreto (REAL et al., 2015).

Por sua vez, os concretos leves confeccionados em questão, podem ser considerados para serem utilizados para fins não estruturais, proporcionando maior conforto térmico e acústico (RASHAD, 2018), contribuindo também para a redução do peso próprio da edificação, possibilitando a adoção de estruturas mais esbeltas, diminuindo o consumo de materiais e contribuindo para uma construção civil mais sustentável.

\section{Conclusões}

O procedimento de fabricação da argila expandida realizado neste estudo, com a exposição do material a uma temperatura de $900{ }^{\circ} \mathrm{C}$, por apenas 30 minutos, mostrou ser adequado para se produzir um produto final, cuja utilização possibilitou a obtenção de um concreto leve, com resistência à compressão semelhante ao do concreto que foi moldado com o uso de uma argila expandida comercial.

As resistências à compressão de ambas as variações de amostras (CAF e CAC) foram semelhantes em todas as idades em que foram realizados os ensaios, tendo os exemplares de CAF apresentado valor médio de resistência ligeiramente superior aos exemplares de CAC somente aos 7 dias de idade.

A utilização de argilas expandidas também não interferiu na cura do concreto, haja vista que o comportamento da resistência à compressão, de ambas as amostras, apresentou a tendência de aumento dos valores em função do avanço da idade dos concretos, como esperado. $O$ uso das argilas expandidas também não causou fragilidade superficial, pois a ruptura das amostras foi do tipo cônico bipartido, ou seja, as fraturas não se concentraram nas superfícies de contato, quando submetidas aos esforços de compressão.

Assim, as argilas expandidas estudadas mostraram contribuir para a produção de concretos leves, sendo recomendado para fins não estruturais, e apresentam vantagens em relação ao agregado convencional como um maior conforto térmico e acústico, além de contribuir para menor peso próprio das edificações, favorecendo projetos de estruturas mais esbeltas, com menor consumo de materiais, para uma construção civil mais sustentável. 


\section{Referências Bibliográficas}

Alexander, M.G., Arliguie, G., Ballivy, G., Bentur, A., Marchand, J. (1999). Engineering and Transport Properties of the Interfacial Transition Zone in Cementitious Composites, RILEM Publications, 72-75.

Associação Brasileira de Normas Técnicas. NBR 6457: Amostras de solo - Preparação para ensaios de compactação e ensaios de caracterização. Rio de Janeiro, 2016.

Associação Brasileira de Normas Técnicas. NBR 7182: Solo - Ensaio de compactação. Rio de Janeiro, 2016.

Associação Brasileira de Normas Técnicas. NBR 6459: Solo - Determinação do limite de liquidez. Rio de Janeiro, 2016.

Associação Brasileira de Normas Técnicas. NBR 6459: Solo - Determinação do limite de plasticidade. Rio de Janeiro, 2016.

Associação Brasileira de Normas Técnicas. NBR NM 248: Agregados - Determinação da composição granulométrica. Rio de Janeiro, 2003.

Associação Brasileira de Normas Técnicas. NBR NM 7211: Agregados para concreto - Especificações. Rio de Janeiro, 2009.

Associação Brasileira de Normas Técnicas. NBR NM 30: Agregado miúdo - Determinação da absorção de água. Rio de Janeiro, 2001.

Associação Brasileira de Normas Técnicas. NBR NM 45: Agregados - Determinação da massa unitária e do volume de vazios. Rio de Janeiro, 2006.

Associação Brasileira de Normas Técnicas. NBR NM 52: Agregado miúdo - Determinação da massa específica e massa específica aparente. Rio de Janeiro, 2009.

Associação Brasileira de Normas Técnicas. NBR NM 46: Agregados - Determinação do material fino que passa na peneira $75 \mu \mathrm{m}$ por lavagem da massa específica e massa específica aparente. Rio de Janeiro, 2011.

Associação Brasileira de Normas Técnicas. NBR 5739: Concreto - Ensaios de compressão de corpos-de-prova cilíndricos. Rio de Janeiro, 2018.

Boldrin, A.J., Machado, R.L., Campos, M.A., Lintz, R.C.C. (2006). Estudo das Propriedades Mecânicas do Concreto com Resíduos de Construção e Demolição Empregados na Produção de Blocos de Concreto. 48은 Congresso Brasileiro do Concreto, Rio de Janeiro, Brasil, setembro 2006.

Burbano-Garcia, C., Hurtado, A., Silva, Y. F., Delvasto, S., Araya-Letelier, G. (2021). Utilization of waste engine oil for expanded clay aggregate production and assessment of its influence on lightweight concrete properties. Constr. and Build. Mater., 273, 121677, 1-17.

Cardoso, L.M. (2017). Tudo sobre os resíduos sólidos da construção civil. Construção civil. Disponível em: https://www.sienge.com.br/blog/residuos-solidos-da-construcao-civil/. Acesso em: 25 out. 2020. Brasil; setembro, 2017.

Helene, P., Levy, S. (2013). Cura do Concreto. Asociación Latinoamericana de Control de Calidad, Patología y Recuperación de la Construcción. Mérida, México. Boletim Técnico n.8, 1-10. Disponível em: http://alconpat.org.br/wp-content/uploads/2012/09/B8-Cura-do-concreto.pdf. Acesso em: 01 nov. 2020.

Neville, A. M., Brooks, J. J. Tecnologia do concreto. 2ª edição, Bookman. Porto Alegre, Brasil, 2013.

Rashad, A.M. (2018). Lightweight expanded clay aggregate as a building material - An overview. Constr. and Build. Mater., 170, 757-775.

Real, S., Bogas, J.A., Pontes, J. (2015). Chloride migration in structural lightweight aggregate concrete produced with different binders, Constr. and Build. Mater., 98, 425-436.

Roufael, G., Beaucour, A.-L., Eslami, J., Hoxha, D., Noumowé, A. (2021). Influence of lightweight aggregates on the physical and mechanical residual properties of concrete subjected to high temperatures. Constr. and Build. Mater., 268, 121221, 1-13.

Sacht, H.M., Rossignolo, J.A., Santos. W.N. (2010). Avaliação da condutividade térmica de concretos leves com argila expandida. Rev. Matéria, 15 (1), 031 - 039. 